\title{
Os Efeitos do Gasto do Governo sobre o Investimento do Setor Privado no Brasil entre 1970 a 2009
}

The Effects of Government Spending on Private Sector Investment in Brazil from 1970 to 2009

\section{Carlos Gilbert Conte Filho ${ }^{a}$}

\begin{abstract}
Resumo: Este artigo analisa se os investimentos das administrações públicas complementam ou substituem (crowding-in ou crowding-out effect) os investimentos do setor privado no Brasil entre 1970 a 2009. Utilizando um modelo de mecanismo de correção de erros, os resultados mostram que os investimentos das administrações públicas apresentam um efeito substitutivo aos investimentos privados. Os resultados mostram também que o crescimento da demanda contribui com os investimentos do setor privado, confirmando a teoria do acelerador do investimento para a economia brasileira no período em análise.
\end{abstract}

Palavras-chave: Investimento; Economia Brasileira; Análise econométrica. Classificação JEL: O11

\begin{abstract}
This article analyzes whether public administration investments complement or replace (crowding-in or crowding-out effect) private sector investments in Brazil between 1970 and 2009. Using an error correction mechanism model, the results show that investments public administrations have a substitute effect for private investments. The results also show that the growth in demand contributes to private sector investments, confirming the investment accelerator theory for the Brazilian economy in the period under analysis.
\end{abstract}

Keywords: Investment; Brazilian economy; Econometric analysis.

JEL Classification: $\mathrm{O} 11$

${ }^{\text {a }}$ Professor adjunto do Departamento de Economia da Universidade Federal de Santa Maria.

E-mail: cgconte@terra.com.br. 


\section{Introdução}

No período entre 1970 a 2009, a economia brasileira apresentou duas fases distintas no que se refere ao crescimento econômico. A primeira vai até o final da década de 1970, que é caracterizada pelo rápido crescimento da atividade econômica do país, sobretudo durante o Milagre Econômico (1968-73), quando a taxa média do crescimento do Produto Interno Bruto (PIB) se situou em torno dos $10 \%$ anuais. Na segunda fase, ou seja, de 1980 até 2009, houve uma retração do crescimento, onde a taxa média do PIB foi ligeiramente superior a $2 \%$ ao ano.

Desde a década de 1930 até a conclusão do II Plano Nacional de Desenvolvimento (com os investimentos sendo realizados de maneira mais intensivas até o final da década de 1970), a economia brasileira foi orientada pelo modelo de Substituição de Importações, em que o Estado possuía papel central como o indutor do crescimento. Este modelo de desenvolvimento, por sua vez, manteve os níveis de crescimento do País em um patamar elevado. Entretanto, a partir da década de 1980, com a crise da dívida externa, o Estado não teve condições de continuar investindo. Isso se manifestou em um longo período de reduzido crescimento aliado a uma alta taxa inflacionária e recessão. Se por um lado o Estado deixou de investir, por outro, os fatores resultantes do quadro macroeconômico da década de 1980 fizeram com que os capitalistas mantivessem uma postura defensiva e avessa a riscos. Os sucessivos fracassos dos planos econômicos da década de 1980 ampliavam as incertezas, induzindo os capitalistas a investirem no setor financeiro em detrimento de investimentos no setor produtivo. O resultado foi a queda da taxa de investimento durante este período, de modo que a taxa do crescimento do PIB se situou em torno dos 2,2\% ao ano na década de 1980, o que ficou muito distante da realidade dos anos 1970.

Na década de 1990, com as diretrizes propostas pelo Consenso de Washington, particularmente após o Plano Real (1994), o Brasil adotou uma política neoliberal deixando a cargo do capital privado muitas das tarefas até então realizadas pelo Estado. Entretanto, o novo modelo de crescimento não resultou em taxas maiores: a economia brasileira cresce em média $2 \%$ ano, entre 1990 a 2009.

Desse modo, partindo do pressuposto de que o investimento privado é uma variável tipicamente endógena que repercute no crescimento dos países, o objetivo geral deste artigo é elaborar uma função investimento e testá-la empiricamente com dados da economia brasileira a fim de analisar o efeito do gasto público sobre o setor privado. Neste sentido, analisar-se-á a influência sobre o investimento privado dos investimentos da Administração Pública, da variação do PIB, da instabilidade da economia, da taxa de juros e da abertura econômica. Para isto, foram estimadas as equações de longo e de curto prazos do período entre 1970 a 2009. Uma das grandes limitações de estudos empíricos no Brasil é a carência de dados. Não obstante, o Instituto Brasileiro de Geografia e Estatística (IBGE) modificou recentemente a metodologia para a elaboração de dados das Contas Nacionais retroagindo em poucos anos. Desse modo, há poucos dados disponíveis a partir da metodologia nova (

os quais são insuficientes para a realização de uma análise econométrica). Da 
metodologia anterior os dados estão restritos ao ano de 2009. Diante dessa limitação, esse estudo utiliza os dados disponíveis entre 1970 a 2009 que viabilizam uma análise empírica e demonstram características estruturais da economia nacional. A opção de excluir o período recente se refere à circunstancial mudança de metodologia por parte do IBGE a partir de 2009, justificando, portanto, o recorte temporal da análise empreendida.

Em economias em desenvolvimento, como o Brasil, muitas vezes o setor público assume um papel significativo no desenvolvimento do país. Neste caso, duas hipóteses surgem quanto à influência do investimento público e das estatais sobre o setor privado, dependendo do tipo de investimento que é realizado. A primeira hipótese é a de que investimentos governamentais em infraestrutura têm caráter complementar (crowding-in). Investimentos deste tipo, em geral, elevam a produtividade de economia, incentivando o setor privado a investir. Os empresários percebem o aprimoramento da infraestrutura como uma ampliação da viabilidade dos projetos de investimentos, minimizando os riscos e elevando os ganhos. A segunda hipótese é a de que o gasto público pode ter influência negativa no investimento privado. Muitos autores acreditam que devido aos mercados financeiros incipientes de países em desenvolvimento - como o Brasil - o gasto público em investimento pode competir com o setor privado pelos recursos, o que resultaria em um caráter de substituição entre o investimento público e privado (crowding-out). A baixa taxa de poupança ou o incipiente sistema financeiro pode gerar competição por recursos escassos, levando o investimento público a se tornar um entrave ao investimento privado. Desse modo, para a análise dos determinantes do investimento privado em países em desenvolvimento como o Brasil, a variável investimento público é utilizada como variável explicativa do investimento privado, podendo, então, identificar se o comportamento do gasto público assume uma postura de substituição ou de complementaridade em relação ao investimento privado.

Este artigo está organizado em três seções, além desta introdução. Na próxima seção é realizada uma discussão da literatura empírica sobre o tema. Na seção três é apresentada a fonte de dados e são realizados os testes empíricos. Por fim, na seção quatro, são apresentadas as conclusões.

\section{Revisão da Literatura Empírica}

A literatura empírica sobre os determinantes do investimento privado no Brasil é relativamente recente. Melo e Rodrigues (1998) discutem, após uma breve descrição de algumas abordagens teóricas sobre a função investimento, quais fatores influenciaram a taxa de investimento privado no Brasil. Para isso, os autores testaram a seguinte função:

$$
I^{P}=f\left(Y, I^{G}, i, P\right)
$$

em que IP é o investimento bruto do setor privado, Y é o produto interno bruto, IG é o investimento bruto do setor público, i é a taxa real de juros e P é a taxa de inflação anual.

De acordo com esta função, espera-se que um aumento do PIB gere um aumento dos investimentos privados, já que mais produção requer mais investimento. A taxa de juros 
deve ter um impacto negativo, pois reflete o custo do capital. A taxa de inflação, uma proxy para a incerteza, deve deprimir os investimentos do setor privado, uma vez que a instabilidade aumenta o preço de espera por novas informações, além de aumentar o risco do investimento. No que tange o investimento privado e público, pode haver uma relação ambígua, pois investimentos públicos em infraestrutura tendem a incentivar o investimento privado, mas, ao mesmo tempo, - em economias em desenvolvimento como a brasileira compete com o setor privado por recursos financeiros escassos.

A partir dos testes econométricos, os autores chegam à conclusão de que há uma relação negativa entre a inflação e os investimentos privados, ainda mais forte do que a influência da taxa de juros sobre os investimentos. Eles apontam que a instabilidade econômica e as alterações bruscas das regras do jogo verificadas na economia brasileira durante todo o período analisado, principalmente a partir dos anos 1980, ampliaram as incertezas sobre as variáveis chaves para a decisão de investimento. Quanto ao efeito do investimento do setor público sobre o investimento privado, houve substituição do setor privado pelo público. Desse modo, para estimular o investimento privado no Brasil, os autores sugerem três políticas, a saber: garantir o crescimento econômico; a fixação das taxas de juros em níveis moderados e; a manutenção da taxa de inflação sob controle, de modo a reduzir a incerteza e gerar credibilidade por parte dos agentes privados.

Visando a analisar a relação entre o investimento público e privado, Rocha e Teixeira (1996) analisam o impacto do investimento público sobre o privado no Brasil. Para isso, utilizam a seguinte função:

$$
\mathrm{I}^{P}=f\left(Y, i, I^{G}\right)
$$

onde IP é o investimento privado, Y é o PIB, i é a taxa de juros e IG é o investimento público.

Os resultados mostraram que o investimento público exerceu, entre 1965 a 1990 , um papel substitutivo aos gastos privados com investimento. O PIB teve um efeito positivo sobre os investimentos. O estudo também mostrou que a taxa de juros é a variável de maior influência sobre o investimento privado, contrariando os resultados de Melo e Rodrigues (1998).

Cruz e Teixeira (1999) também analisaram o impacto dos investimentos públicos sobre o investimento privado no Brasil. O período analisado foi de 1947 a 1990. Eles apontam que o investimento público pode ter efeito complementar sobre o investimento privado, principalmente quando esses são realizados em infraestrutura. Os autores argumentam que o Estado é o agente mais disposto a fazer investimentos de alto risco e em setores que requerem grandes volumes de capital e com longo período de maturação. No Brasil, este tipo de investimento não atrai o capital privado. As razões para explicar esse fenômeno partem do risco, mas também - como indicado por Pindyck e Solimano (1993) - pelo limitado tamanho do mercado secundário brasileiro e pelo incipiente mercado financeiro voltado para o longo prazo. Investimentos em áreas infraestruturais ou em projetos de grande porte demandam grande volume de capital e longo período de maturação. Desse modo, a atuação do Estado na economia se torna de suma importância 
para o desenvolvimento do país. Os autores utilizam a seguinte função para estimar os determinantes do investimento privado:

$$
I^{P}=f\left(Y, i, I^{G}\right)
$$

onde Y é o produto agregado, como uma proxy da expectativa de demanda futura, i é a taxa de juros e IG o investimento público.

Os resultados mostram que a expectativa de demanda é o fator principal na determinação do investimento privado e, que os investimentos públicos foram substitutivos ao investimento privado no curto prazo, embora no longo prazo haja complementaridade entre eles. Outro resultado é que o investimento privado no Brasil não parece ser muito sensível a taxas de juros, pois o coeficiente se mostrou estatisticamente não significativo. Portanto, há substituição no curto prazo e complementariedade no longo prazo. Na mesma linha de pesquisa, Ribeiro e Teixeira (2001) analisaram os determinantes do investimento privado no Brasil no período entre 1956 e 1996. Os autores empregaram a seguinte função investimento:

$$
I^{P}=f\left(Y, i, I^{G}, C, D, E, M\right)
$$

em que, IP é o investimento do setor privado, Y é o produto doméstico, i é a taxa real de juros, IG é o investimento público, C é o crédito disponível para investimento, D é o tamanho do déficit externo, E é a taxa de câmbio e M é a estabilidade macroeconômica.

A partir dos resultados, os autores criticam a proposta do Consenso de Washington de reduzir o papel do Estado visto que, mesmo em um ambiente globalizado, o crescimento econômico necessita da intervenção do governo na economia.

Os resultados também mostram que o equilíbrio da política econômica é benéfico para incentivar os investimentos do setor privado (algo que envolveria uma apropriada taxa real de juros, uma taxa de inflação próxima a praticada pelos parceiros de negócios, uma taxa de câmbio competitiva e previsível), assim como estratégias de longo prazo nos projetos de investimento público.

De acordo com os autores, no Brasil tem-se demonstrado a importância dos créditos de longo prazo de bancos de desenvolvimento; assim como a predominância dos benefícios dos investimentos públicos incentivando os investimentos do setor privado; e os efeitos negativos da desvalorização da moeda corrente no investimento.

A partir dos resultados obtidos, os autores apontam três maneiras de induzir o aumento do investimento privado no Brasil, são elas:

1. Aumentando a atividade econômica;

2. Aumentando o prazo de financiamento dos créditos; e

3. Aumentando investimentos em bens públicos.

Com o objetivo de discutir o impacto da carga tributária sobre os investimentos no Brasil, o trabalho de Santos e Pires (2007) analisou, empiricamente, a influência desta variável sobre os investimentos privados no Brasil, com dados trimestrais entre 1995 a 2006. 
Os autores argumentam que, de fato, a partir de 1995 os sucessivos aumentos da carga tributária podem ter sido um dos responsáveis pelo baixo índice de investimentos no Brasil. Entretanto, para analisar a veracidade desta afirmação, realizam uma investigação empírica utilizando a seguinte função investimento:

$$
I^{P}=f\left(I^{P-E}, I^{G}, I^{G+E}, Y, P^{K}, T\right)
$$

onde IP é o investimento privado, IP-E é o investimento privado excluindo as estatais federais, IG é o investimento público, IG+E é o investimento público, incluindo as estatais, Y é o PIB, PK é uma proxy dos preços relativos dos bens de capital e T é a carga tributária.

Após a realização do teste de raiz unitária e averiguação da não estacionaridade das séries, os autores utilizam o procedimento de Johansen (1991) - metodologia VAR - para estimar a equação de cointegração. Os resultados dos testes mostram que a elasticidadeproduto do investimento privado brasileiro é elevada (próximo de dois), e que a elasticidade-carga tributária do investimento privado brasileiro é significativa e próxima de menos um. Quanto às outras variáveis incluídas na função testada, os autores não fazem quaisquer comentários sobre a influência que exerceram sobre o investimento privado brasileiro no período em questão.

Com relação ao efeito que o gasto público em infraestrutura exerce sobre o PIB real, Ferreira (1996) faz uma análise empírica com dados para a economia brasileira entre 1970 a 1993. O objetivo do autor é mensurar o impacto que investimentos públicos realizados em infraestrutura exercem sobre o produto da economia brasileira.

$\mathrm{O}$ autor destaca que investimentos em infraestrutura influenciam positivamente novos investimentos do setor privado, mesmo que o efeito não seja imediato, como ocorre em países desenvolvidos. Entretanto, o estudo mostra que, no Brasil, esse tipo de investimento se reduziu nos últimos anos (a exceção do setor de telecomunicações).

Para realizar o teste empírico, foram, então, utilizadas duas séries de investimento: investimento realizado pelas estatais do setor de infraestrutura e a série do total dos investimentos das estatais e das administrações públicas. Ambas as séries foram depreciadas a $6 \%, 8 \%$ e $10 \%$ como mostra a equação abaixo:

$$
Y^{R}=f\left(K I_{6}, K I_{8}, K I_{10}, K T_{6}, K T_{8}, K T_{10}\right)
$$

onde YR é o PIB real, KI é o investimento das estatais realizado em infraestrutura e KT é o investimento das estatais e das administrações públicas.

A metodologia utilizada pelo autor foi a dos vetores autorregressivos (VAR) desenvolvida por Johansen (1991). Os resultados confirmam a teoria e mostram que, no Brasil, os gastos em infraestrutura teriam efeito positivo sobre a evolução futura do PIB real, visto que beneficiariam os investimentos privados e o trabalho. Desse modo, os resultados - juntamente com a análise dos setores infraestruturais realizada pelo autor revelam perspectivas pessimistas quanto ao crescimento da economia brasileira, uma vez que investimentos em dois dos três setores analisados foram declinantes durante o período analisado pelo autor (energia e transportes).

Ao analisar os trabalhos de Rocha e Teixeira (1998) e de Ribeiro e Teixeira (2001) 
é possível observar que a taxa de juros (custo do capital) exerce efeitos distintos em cada uma das pesquisas citadas. O trabalho de Rocha e Teixeira utiliza a correção monetária ou seja, uma taxa de juros de curto prazo para mensurar o custo do capital. $\mathrm{O}$ autor conclui que há um efeito forte e negativo do custo do capital sobre o investimento do setor privado. Ribeiro e Teixeira, por sua vez, utilizam o custo do capital aplicado nas operações realizadas pelo Banco Nacional de Desenvolvimento Econômico e Social (BNDES), ou seja, utilizam uma taxa de juros de longo prazo. Os autores concluem que, para que o investimento do setor privado aumente, é necessário aumentar o prazo de financiamento que é superior quando comparado ao financiamento realizado através do setor financeiro e que o custo do capital não influencia o investimento do setor privado.

Observa-se, portanto, que há diferenças entre os trabalhos citados acerca do custo do capital utilizando: ora se utiliza a taxa de juros de curto prazo, ora a taxa de juros de longo prazo. Neste sentido, Paul Davidson (1986) traz à tona a discussão acerca do tema. Segundo o autor, o financiamento de curto prazo é utilizado sempre que os empresários desejam aumentar o fluxo de investimentos, enquanto o financiamento de longo prazo parte de recursos públicos a fim de aumentar a liquidez da economia. Ou seja, é necessário distinguir qual tipo de investimento está sendo feito: se é a realização do investimento através da compra de bens de capital ou se o investimento está sendo feito pela empresa que fabrica o bem de capital que está sendo demandado por uma outra empresa. Segundo o autor, as empresas que demandam bens de capital utilizam o financiamento de longo prazo para realizar o investimento (portanto, o custo do capital é o de longo prazo). A empresa que produz bens de capital, por sua vez, pode, ao longo do processo produtivo (que é longo e caro) necessitar de mais recursos para concretizar a produção do bem de capital encomendado (tal como recursos para fluxo de caixa). Sendo assim, ao longo do processo produtivo, a empresa que fabrica os bens de capital pode necessitar de recursos adicionais os quais obterá junto ao sistema financeiro. Portanto, contratará recursos com custos de curto prazo.

A revisão da literatura empírica tem o propósito de indicar uma direção geral para a elaboração dos elementos necessários à estimação da função que relaciona os investimentos privados e seus determinantes, que está apresentada na próxima seção.

\section{Estimativa da Função Investimento}

O objetivo desta seção é realizar o teste empírico dos determinantes do investimento privado brasileiro entre 1970 a 2009 . Foi realizado este corte temporal em virtude da disponibilidade de dados e da mudança metodológica realizada nos dados a partir de 2010 pelo Instituto Brasileiro de Geografia e Estatística (IBGE). Em um primeiro momento será apresentada a função a ser utilizada, assim como serão esclarecidos quais são os sinais esperados das variáveis, além de apresentar a metodologia que será utilizada, para que, num segundo momento, sejam realizados os testes empíricos. Para analisar os determinantes do investimento privado no Brasil é utilizada a seguinte função:

$$
I^{P}=f\left(Y, I^{G}, \text { Inst }, i_{r}, D\right)
$$


Onde:

IP = investimento bruto do setor privado;

$\mathrm{Y}=$ taxa de crescimento do produto interno bruto

IG = investimento bruto das administrações públicas;

Inst = Instabilidade da economia;

$\mathrm{i}_{\mathrm{r}}=$ taxa de juros real;

$\mathrm{D}=$ variável dummy para a abertura comercial (com valor zero para o período entre 1970 a 1993 e valor um para o período entre 1994 a 2009).

A função investimento será estimada em relação ao PIB, de modo que as variáveis investimento bruto do setor privado e investimento bruto das administrações públicas são transformadas em taxa em relação ao PIB. Todos os dados, a exceção da taxa de juros real, foram obtidos junto ao banco de dados do IpeaData. Para a taxa de juros nominal foi utilizada a série da taxa de juro nominal dos Certificados de Depósito Bancário (CDB) obtido junto ao IpeaData. Segundo Davidson (1986), a taxa de juros de longo prazo seria a mais apropriada neste estudo. Entretanto, não há dados disponíveis da Taxa de Juros de Longo Prazo (TJLP) para o período em análise de modo que, assim como no estudo de Rocha e Teixeira (1996) e de Cruz e Teixeira (1999), utiliza-se neste estudo a taxa de juros de curto prazo. Para construir a série temporal para a taxa de juros real foi utilizado a série temporal da taxa de juro nominal $(\mathrm{CDB})$ e aplicada à equação abaixo:

$$
i_{r}=\left(\frac{\left(1+i_{n}\right)}{(1+\pi)}\right)-1
$$

em que ir é a taxa de juros real, in é a taxa de juros nominal e $\pi$ é a inflação (IGP-DI).

Os sinais esperados para os coeficientes das variáveis independentes são descritos a seguir. De acordo com a literatura econômica, o investimento público pode influenciar o comportamento do investimento privado tanto de modo positivo (crowding-in) como negativo (crowding-out). O impacto que o gasto público exerce sobre o investimento privado depende do tipo de investimento que o governo realiza, assim como do volume disponível para que esses investimentos ocorram. Investimentos governamentais em infraestrutura tendem a incentivar o investimento privado. Contudo, ao mesmo tempo, em economias em desenvolvimento como a brasileira, podem significar uma disputa por recursos escassos com o setor privado. Desse modo, não se pode prever, ex ante, qual o sinal esperado para esta variável.

A combinação entre inflação, taxa de juros e taxa de câmbio é o indicador utilizado para avaliar o impacto da instabilidade econômica sobre o investimento privado. $\mathrm{O}$ sinal esperado para o coeficiente de instabilidade é negativo, visto que um ambiente mais instável incentiva os capitalistas a manterem os recursos no sistema financeiro em detrimento da economia real, tal como postula a teoria Keynesiana. Para criar a série da instabilidade da economia foram utilizados os dados referentes à inflação (IGP-DI), divulgada pela Fundação Getúlio Vargas, a taxa de juros real e a taxa de câmbio (R\$/Dólar), venda média ao fim do período, e aplicada a seguinte fórmula a fim de obter os dados anuais: 


$$
\text { inst }=(1+\pi)+\Delta \mathrm{r}+\Delta \mathrm{E}
$$

Quanto à taxa de juros, uma elevação desta tende a incentivar que os recursos permaneçam no sistema financeiro inibindo os investimentos. Isto posto, o sinal esperado para este coeficiente é negativo.

O sinal esperado para o coeficiente da taxa de crescimento do produto é positivo, pois essa é uma proxy das condições de demanda. O sinal esperado para a dummy da abertura comercial é positivo, pois um aumento da concorrência tende a pressionar as empresas a ampliarem os investimentos de modo que, se não o fizerem, perderão espaço no mercado e os lucros futuros serão menores. No limite, uma firma que não investe em capital fixo frente à maior concorrência (investimentos que permitam produzir bens com maior qualidade), tenderá a desaparecer do mercado (pois será absorvida pela concorrência de empresas que agregam o desenvolvimento tecnológico a seus produtos ou, que produzam a um custo menor). A tabela 1 resume o efeito que cada variável exerce sobre o investimento, assim como o sinal esperado de cada uma delas.

Tabela 1: Variáveis Incluídas na Função Investimento e os Sinais Esperados

\begin{tabular}{c|c}
\hline \hline Variável & Sinal Esperado \\
\hline Investimento das administrações públicas $\left(\mathrm{I}^{\mathrm{G}}\right)$ & Indeterminado a priori \\
\hline Produto Interno Bruto $(\mathrm{Y})$ & Positivo \\
\hline Instabilidade da Economia (Inst) & Negativo \\
\hline Taxa de Juros Real $\left(\mathrm{i}_{\mathrm{r}}\right)$ & Negativo \\
\hline Dummy para a Abertura Comercial (D) & Positivo \\
\hline \hline
\end{tabular}

Fonte: Elaboração Própria.

Utilizando o pacote econométrico E-views 10 , foram realizados os testes de raiz unitária Augmented Dickey-Fuller (ADF), Phillips-Perron (PP) e Kwiatkowski-PhillipsSchmidt-Shin (KPSS) das séries de tempo em análise neste estudo. O número de defasagens foi definido a partir da minimização do Critério de Schwartz. Os valores críticos para estabelecer a existência ou não de raiz unitária foram tabulados por MacKinnon (1996) e utilizou-se como referência para a determinação da existência (ou não) de raiz unitária um valor crítico de 5\%. Por sua vez, para determinar o nível de integração das variáveis utilizou-se a hipótese de que todas elas possuíam intercepto.

Na maioria dos testes a hipótese nula é de que a série tenha raiz unitária e, portanto, não é estacionária. No teste KPSS, por sua vez, a hipótese nula é de que não existe raiz unitária. A Tabela 2 sintetiza os resultados: 
Tabela 2: Teste de Raiz Unitária Sobre as Variáveis

\begin{tabular}{|c|c|c|c|c|}
\hline Variável & $\begin{array}{c}\text { ADF } \\
\text { (valor crítico: } 5 \%)\end{array}$ & $\begin{array}{c}\text { PP } \\
\text { (valor crítico: } 5 \%)\end{array}$ & $\begin{array}{c}\text { KPSS } \\
\text { (valor crítico: } 5 \% \text { ) }\end{array}$ & $\begin{array}{c}\text { Grau de } \\
\text { Integração }\end{array}$ \\
\hline $\mathbf{I}^{\mathbf{P}}$ & $\begin{array}{c}-2,519 \\
(-2,938)\end{array}$ & $\begin{array}{c}-2,495 \\
(-2,938)\end{array}$ & $\begin{array}{c}0,492 \\
(0,463)\end{array}$ & \multirow{2}{*}{$\mathrm{I}(1)$} \\
\hline $\mathbf{D}\left(\mathbf{I}^{\mathrm{P}}\right)$ & $\begin{array}{c}-7,834 \\
(-2,941)\end{array}$ & $\begin{array}{c}-7,743 \\
(-2,941)\end{array}$ & $\begin{array}{c}0,377 \\
(0,463)\end{array}$ & \\
\hline $\mathbf{I}^{\mathrm{G}}$ & $\begin{array}{c}-2,188 \\
(-2,938)\end{array}$ & $\begin{array}{c}-2,188 \\
(-2,938)\end{array}$ & $\begin{array}{c}0,489 \\
(0,463)\end{array}$ & \multirow{2}{*}{$\mathrm{I}(1)$} \\
\hline $\mathbf{D}\left(\mathbf{I}^{\mathrm{G}}\right)$ & $\begin{array}{c}-5,689 \\
(-2,948) \\
\end{array}$ & $\begin{array}{c}-5,566 \\
(-2,941) \\
\end{array}$ & $\begin{array}{c}0,177 \\
(0,463) \\
\end{array}$ & \\
\hline $\mathbf{Y}$ & $\begin{array}{c}-3,596 \\
(-2,938)\end{array}$ & $\begin{array}{c}-3,472 \\
(-2,938)\end{array}$ & $\begin{array}{c}0,456 \\
(0,463)\end{array}$ & $\mathrm{I}(0)$ \\
\hline INST & $\begin{array}{c}-1,545 \\
(-2,943)\end{array}$ & $\begin{array}{c}-2,527 \\
(-2,938)\end{array}$ & $\begin{array}{c}0,149 \\
(0,463)\end{array}$ & \multirow{2}{*}{$\mathrm{I}(1)$} \\
\hline D(INST) & $\begin{array}{c}-7,598 \\
(-2,943)\end{array}$ & $\begin{array}{c}-9,587 \\
(-2,941)\end{array}$ & & \\
\hline $\mathbf{i}_{\mathbf{r}}$ & $\begin{array}{c}-2,497 \\
(-2,938)\end{array}$ & $\begin{array}{c}-2,423 \\
(-2,938)\end{array}$ & $\begin{array}{c}0,183 \\
(0,463)\end{array}$ & \multirow{2}{*}{$\mathrm{I}(1)$} \\
\hline $\mathbf{D}(\mathbf{r})$ & $\begin{array}{c}-6,059 \\
(-2,943)\end{array}$ & $\begin{array}{c}-9,775 \\
(-2,941)\end{array}$ & & \\
\hline
\end{tabular}

Fonte: Resultados gerados pelo E-Views 10.

Como das cinco séries temporais utilizadas neste estudo, quatro apresentaram raiz unitária, o próximo passo é aplicar a metodologia de Johansen (1991) para verificar se existe ao menos um vetor cointegrador e, assim, garantir que a regressão tenha significado econômico, isto é, garantir que a regressão não seja espúria. Contudo, é necessário averiguar previamente qual é o melhor número de defasagens a ser incluída no VAR. Para este propósito tem-se a tabela 3:

Tabela 3: Definição do Número de Defasagens da VAR

\begin{tabular}{c|c|c|c|c|c|c}
\hline \hline Defasagem & LogL & LR & FPE & AIC & SC & HQ \\
\hline $\mathbf{0}$ & 140,873 & NA & $2,75 \mathrm{e}-11$ & $-7,290$ & $-7,029$ & $-7,198$ \\
\hline $\mathbf{1}$ & 260,713 & 194,335 & $3,04 \mathrm{e}-13$ & $-11,822$ & $-9,993^{*}$ & $-11,177$ \\
\hline $\mathbf{2}$ & 320,316 & $77,322^{*}$ & $9,96 \mathrm{e}-14 *$ & $-13,098$ & $-9,702$ & $-11,900^{*}$ \\
\hline $\mathbf{3}$ & 361,671 & 40,237 & $1,18 \mathrm{e}-13$ & $-13,387 *$ & $-8,424$ & $-11,637$ \\
\hline \hline
\end{tabular}

Fonte: Resultados gerados pelo E-Views 10. 
O número de defasagens adotadas neste estudo são duas como sugerem a maioria dos testes (testes LR, FPE e HQ). O próximo passo consiste em realizar o teste do traço e o teste do máximo autovalor. As tabelas quatro e cinco apresentam esses testes de cointegração:

Tabela 4: Testes de Cointegração do Traço

\begin{tabular}{c|c|c|c}
\hline \hline $\begin{array}{c}\text { Hipótese do no de Equações } \\
\text { cointegradoras }\end{array}$ & Autovalor & Traço Estatístico & Valor Crítico a 5\% \\
\hline Nenhuma & 0,782 & 145,926 & 95,753 \\
\hline No máximo 1 & 0,633 & 89,421 & 69,818 \\
\hline No máximo 2 & 0,510 & 52,320 & 47,856 \\
\hline No máximo 3 & 0,307 & 25,886 & 29,797 \\
\hline No máximo 4 & 0,168 & 12,316 & 15,494 \\
\hline No máximo 5 & 0,137 & 5,487 & 3,841 \\
\hline \hline
\end{tabular}

Fonte: Resultados gerados pelo E-Views 10.

O teste do traço indica que existem, no máximo, três equações cointegradoras a $5 \%$ de significância, o que garante que a regressão não é espúria. O teste do máximo autovalor (Tabela 5) confirma os resultados apresentados pelo teste do traço de que a função não é espúria. Entretanto, o teste do máximo autovalor indica a existência de apenas duas equações cointegradoras a $5 \%$ de significância.

Tabela 5: Teste de Cointegração do Máximo Autovalor

\begin{tabular}{c|c|c|c}
\hline \hline $\begin{array}{c}\text { Hipótese do no de Equações } \\
\text { cointegradoras }\end{array}$ & Autovalor & $\begin{array}{c}\text { Máximo Autovalor } \\
\text { Estatístico }\end{array}$ & $\begin{array}{c}\text { Valor Crítico a } \\
\mathbf{5 \%}\end{array}$ \\
\hline Nenhuma & 0,782 & 56,504 & 40,077 \\
\hline No máximo 1 & 0,633 & 37,101 & 33,876 \\
\hline No máximo 2 & 0,510 & 26,433 & 27,584 \\
\hline No máximo 3 & 0,307 & 13,570 & 21,131 \\
\hline No máximo 4 & 0,168 & 6,828 & 14,264 \\
\hline No máximo 5 & 0,137 & 5,487 & 3,841 \\
\hline \hline
\end{tabular}

Fonte: Resultados gerados pelo E-Views 10.

A etapa seguinte consiste em estimar o vetor cointegrador que governa o comportamento de longo prazo das variáveis envolvidas na análise. A função de longo prazo para as variações do investimento privado no Brasil é apresentada a seguir (Tabela 6): 
Tabela 6: Vetor Cointegrador (Coeficientes e Estatística t)

\begin{tabular}{c|c|c}
\hline \hline Variável & Coeficiente de Ajustamento de Longo Prazo & Estatística t \\
\hline IP (-1) & 0,424 & $2,518 \mathrm{a}$ \\
\hline IP (-2) & 0,041 & 0,264 \\
\hline IG (-1) & 0,086 & $1,922 \mathrm{a}$ \\
\hline IG (-2) & $-0,126$ & $-2,572 \mathrm{a}$ \\
\hline Y (-1) & 0,041 & $1,945 \mathrm{a}$ \\
\hline Y (-2) & 0,021 & $0,943 \mathrm{c}$ \\
\hline Inst (-1) & $-2,67 \mathrm{E}-05$ & $-0,231$ \\
\hline Inst (-2) & 0,0001 & $0,880 \mathrm{c}$ \\
\hline $\mathbf{i}_{\mathbf{r}} \mathbf{( - 1 )}$ & $-0,005$ & $-1,715 \mathrm{a}$ \\
\hline $\mathbf{i}_{\mathbf{r}} \mathbf{( - 2 )}$ & 0,0003 & 0,079 \\
\hline D (-1) & $-0,022$ & $-3,419 \mathrm{a}$ \\
\hline D (-2) & 0,017 & $2,518 \mathrm{a}$ \\
\hline C & 0,022 & $2,505 \mathrm{a}$ \\
\hline \hline
\end{tabular}

Fonte: Resultados gerados pelo E-Views 10.

Nota: "a" e "c" indicam, respectivamente, que os parâmetros estimados são significativamente diferentes de zero ao nível de $5 \%(1,1673)$ e $10 \%(0,68066)$.

Os resultados obtidos mostram que o investimento do setor privado do ano imediatamente anterior influencia positivamente novos investimentos do setor privado. De acordo com os testes, o aumento de $1 \%$ do investimento privado do ano imediatamente anterior gera um acréscimo de $0,42 \%$ na formação bruta de capital fixo do setor privado no longo prazo.

Quanto ao investimento das administrações públicas, o investimento público realizado no período prévio afeta de modo positivo, porém marginalmente o investimento do setor privado. De acordo com os testes, o aumento de $1 \%$ do investimento público do ano previamente anterior gera um acréscimo de $0,08 \%$ na formação bruta de capital fixo. Por isso, ele é complementar. Entretanto, o investimento público realizado em dois períodos anteriores afeta negativamente o investimento privado no longo prazo. De acordo com os testes, o aumento de $1 \%$ do investimento público com duas defasagens gera um decréscimo de $0,12 \%$ na formação bruta de capital fixo do setor privado. Portanto, há um efeito substitutivo dos investimentos entre eles, inclusive superando o ganho gerado no ano imediatamente anterior.

Quanto à influência que o PIB exerce sobre os investimentos do setor privado, uma elevação de $1 \%$ no produto provoca uma elevação entre $0,04 \%$ a $0,02 \%$ na formação bruta de capital fixo do setor privado. 
Os resultados mostram que a instabilidade ocorrida há dois anos influencia positivamente (mesmo que de modo marginal) o investimento do setor privado, o que vai contra o resultado esperado. De acordo com os testes, o aumento de $1 \%$ na instabilidade da economia gera um acréscimo de $0,00015 \%$ na formação bruta de capital fixo. Uma possível explicação para o sinal encontrado diferente do previsto passa pelo pressuposto de que o empresário brasileiro segue um planejamento para realizar os investimentos. Neste sentido, a incerteza presente no ambiente econômico, usual na economia brasileira, não desvia o planejamento previamente estabelecido para a realização do investimento. Sendo assim, apenas o custo do capital se torna relevante e, como se verifica nos resultados obtidos, este sim influencia negativamente o investimento do setor privado. De acordo com os resultados, um aumento da taxa de juros real faz com que o investimento do setor privado cais. A regressão aponta que o aumento de $1 \%$ na taxa de juros real gera um decréscimo de $0,005 \%$ na formação bruta de capital fixo do setor privado.

Os resultados também revelam que o aumento da concorrência internacional influencia o investimento do setor privado de modo negativo no primeiro ano e positivo no segundo ano. A função estimada indica que $88,75 \%$ das variações do investimento privado de longo prazo são explicadas pelas variáveis significativas geradas pelo modelo.

O último passo da metodologia de Johansen, uma vez constatada a existência do vetor cointegrador, é estimar o modelo de correção de erros (VEC) e verificar como as variáveis se ajustam a cada período de tempo e, assim, prever a relação de curto prazo entre elas. Para estimar o VEC foi utilizado mais uma vez dois períodos de defasagens nas séries temporais. Na Tabela 7 estão listadas todas as equações de curto prazo.

Dentre todos os coeficientes estimados, o investimento privado e o investimento público se mostraram estatisticamente significativos na segunda defasagem; enquanto o PIB, a taxa de juros e a abertura comercial na primeira defasagem. A função estimada indica que $71,41 \%$ das variações do investimento privado de curto prazo são explicadas pelas variáveis significativas geradas pelo modelo de correção de erros.

O coeficiente de curto prazo estimado para a formação bruta de capital fixo do setor privado indica que o investimento realizado pelo próprio setor faz com que esses se elevem em $0,27 \%$ nos períodos subsequentes. Por sua vez, um aumento de $1 \%$ nos investimentos do setor público provoca uma queda de $0,24 \%$ nos investimentos do setor privado. Isso indica que, no curto prazo, há substituição entre o setor privado e os investimentos públicos.

O coeficiente de curto prazo estimado para o PIB mostra que o acréscimo de $1 \%$ desta variável implica em uma redução de $0,04 \%$ no investimento privado de curto prazo. Um aumento de $1 \%$ na taxa de juros real, por sua vez, implica em uma queda do investimento privado no curto prazo entre 0,002 a $0,005 \%$. Por fim, abertura comercial acarreta a queda do investimento privado no curto prazo. 
Tabela 7: Vetor de Correção de Erros (VEC)

\begin{tabular}{|c|c|c|}
\hline Variável & $\begin{array}{c}\text { Coeficiente de ajustamento de } \\
\text { curto prazo }\end{array}$ & Estatística $\mathbf{t}$ \\
\hline Investimento do setor privado $\left(\mathrm{I}_{t-1}\right)$ & 0,071 & 0,393 \\
\hline Investimento do setor privado $\left(I^{P}{ }_{t-2}\right)$ & 0,270 & $1,549^{\mathrm{a}}$ \\
\hline $\begin{array}{l}\text { Investimento das administrações } \\
\text { públicas }\left(I_{t-1}^{G}\right)\end{array}$ & $-0,006$ & $-0,098$ \\
\hline $\begin{array}{l}\text { Investimento das administrações } \\
\text { públicas }\left(I^{G} t-2\right)\end{array}$ & $-0,240$ & $-3,194^{\mathrm{a}}$ \\
\hline PIB $\left(Y_{t-1}\right)$ & $-0,041$ & $-1,075^{\mathrm{c}}$ \\
\hline $\operatorname{PIB}\left(Y_{t-2}\right)$ & $-0,003$ & $-0,142$ \\
\hline Instabilidade da Economia (Inst I -1$)$ ) & $4,91 \mathrm{E}-05$ & 0,435 \\
\hline Instabilidade da Economia (Inst t-2) & $1,15 \mathrm{E}-05$ & 0,078 \\
\hline Taxa de Juros $\left(\mathbf{r}_{t-1}\right)$ & $-0,005$ & $-1,529^{a}$ \\
\hline Taxa de Juros $\left(r_{t-2}\right)$ & $-0,003$ & $-0,899^{c}$ \\
\hline Dummy: abertura comercial $\left(D_{t-1}\right)$ & $-0,017$ & $-3,058^{a}$ \\
\hline Dummy: abertura comercial ( $\left.\mathrm{D}_{\mathrm{t}-2}\right)$ & 0,004 & 0,548 \\
\hline Constante (c) & $9,20 \mathrm{E}-05$ & 0,137 \\
\hline Coeficiente de ajustamento $(\mu)$ & $-0,224$ & $-2,321^{\mathrm{a}}$ \\
\hline
\end{tabular}

Fonte: Resultados gerados pelo E-Views 10 .

Nota: "a" e "c" indicam, respectivamente, que os parâmetros estimados são significativamente diferentes de zero ao nível de 5 e $10 \%$.

Para testar a estabilidade dos modelos, as raízes dos polinômios formados na construção do VAR, devem ser todas maiores que um, em módulo, o software aqui utilizado, no entanto, as encontra invertidas. Assim sendo, devem todas estar dentro do círculo unitário. Se isto acontece, pode-se dizer que o modelo é adequado.

Conforme pode ser observado pela Figura 1 que mostram as raízes inversas dos polinômios característicos dos processos $\mathrm{AR}$, todas as raízes dos modelos VAR, estão dentro do círculo, assim o modelo VAR aqui especificado pode ser considerado válido. 


\section{Figura 1: Raízes Inversas dos Polinômios Característicos dos Processos AR}

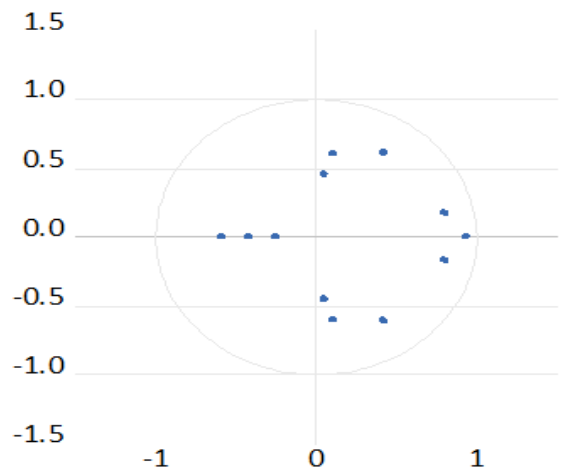

Fonte: Resultados gerados pelo E-Views 10.

Por fim, pode-se observar o impacto que um choque positivo nas variáveis exerce sobre o investimento do setor privado. Para esta análise, utiliza-se da função impulsoresposta a qual é apresentada na Figura 2.

A função impulso-resposta aplicada na VAR aqui estimada mostra que o efeito de um choque positivo isolado no investimento público faz com que o investimento privado inicialmente aumente no primeiro e segundo ano para, em seguida, entre o terceiro e sexto ano cair.

Em relação ao efeito de um choque isolado positivo na variável PIB, observa-se que o investimento privado se torna positivo ao longo dos anos subsequentes. Levando-se em conta a função impulso-resposta que um choque isolado positivo na instabilidade sobre o investimento privado, observa-se que após o choque até o segundo ano o efeito é positivo. Somente no terceiro ano o impacto se torna negativo, perdurando assim pelos próximos anos.

O impacto que um choque isolado positivo na taxa de juros exerce sobre o investimento do setor privado mostra que o efeito substancialmente negativo até o quinto ano, perdendo vigor a partir de então. Por fim, o efeito de um choque isolado positivo na abertura comercial sobre o investimento privado é negativo ao longo de todos os anos subsequentes. 


\section{Figura 2: Função Impulso-Resposta sobre o Investimento Privado}

Response of IP to IG

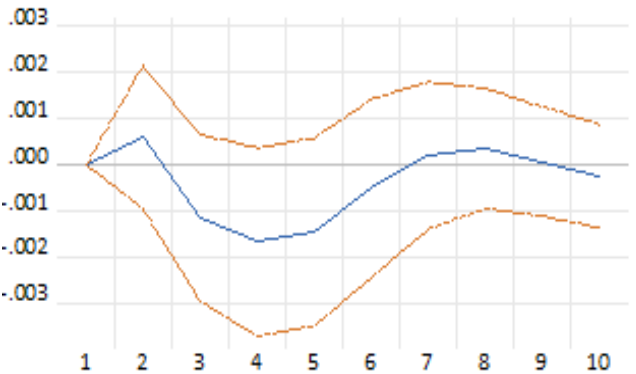

Response of IP to INST

.003

.002

.001

.000

.001

. .002

.003

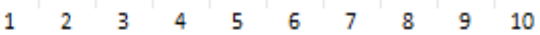

Response of IP to DUM

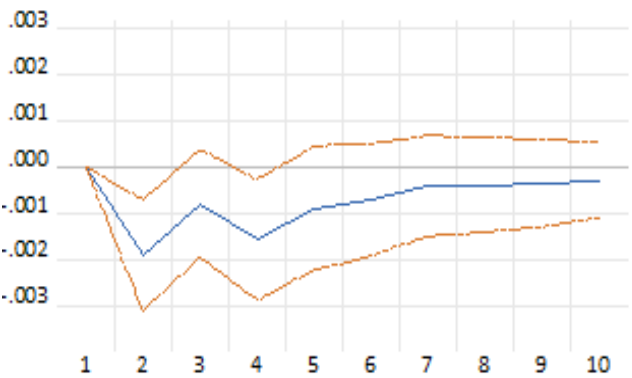

Response of IP to Y

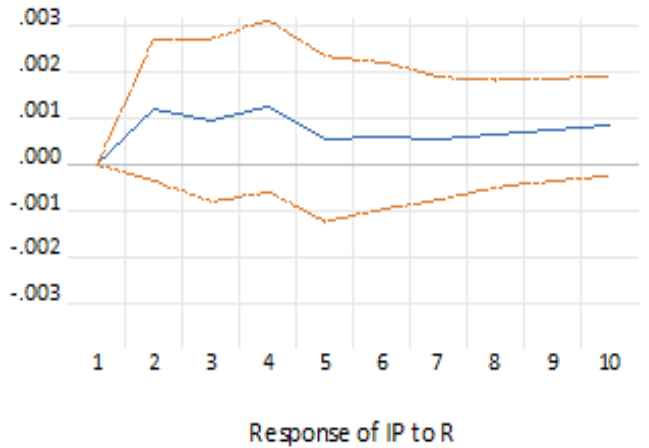

.003

.002

.001

.000

$-.001$

$-.002$

$-.003$

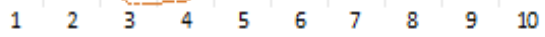

Fonte: Resultados gerados pelo E-Views 10. 


\section{Conclusão}

O presente artigo realizou uma análise empírica dos determinantes do investimento privado na economia brasileira entre 1970 a 2009. Os resultados mostram que o gasto público competiu com os investimentos do setor privado, causando substituição entre eles tanto no curto, como no longo prazo. O efeito crowding-out pode ter ocorrido em virtude da competição por recursos escassos ou pelo fato de os investimentos públicos terem ocorrido em setores onde o capital privado poderia ter atuado.

Os testes também apontaram para o fato de que a demanda eleva os investimentos do setor privado no longo prazo, o que pode ser atribuído ao efeito acelerador dos investimentos. Desse modo, um maior crescimento econômico pode levar a um círculo virtuoso dos investimentos, impulsionando a um maior crescimento.

Quanto à abertura comercial, os resultados mostram que, na primeira metade dos anos 1990, os investimentos se reduziram à medida que as empresas nacionais ficaram expostas a um ambiente com maior nível de competição. Em verdade, a abertura comercial provocou desemprego e a ampliação da recessão em um primeiro momento. Tal assertiva fica evidente quando se exerce um choque sobre esta variável e se observa o resultado sobre o investimento privado.

Quanto à elevação da taxa de juros, os resultados mostram que o impacto de curto e de longo prazo é negativo, mesmo que marginal (confirmando a teoria econômica). O texto contribui com a literatura ao indicar quais devem ser as políticas econômicas do governo em busca de níveis sustentados de crescimento do investimento privado e, consequentemente, do produto. Em períodos de crise, tal qual se encontra a economia brasileira atualmente, o resultado aqui apresentado é determinante: o governo deveria ponderar os investimentos públicos em setores pontuais, visando o crescimento do investimento privado e, consequentemente, um maior crescimento do produto no futuro. Além disso, uma política de manutenção das taxas de juros em um baixo patamar contribuiria para o crescimento. 


\section{Referências}

AGÉNOR, P. R. The Economics of Adjustment and Growth. San Diego: Academic Press, 2000.

BACHA, E. L.; BONELLI, R. Uma interpretação das causas da desaceleração econômica do Brasil. Revista de Economia Política, vol. 25, no3, p. 163-189, 2005.

DOI: https://doi.org/10.1590/S0101-31572005000300001

BACEN (2018). BANCO CENTRAL DO BRASIL. Disponível em <www.bacen.gov.br> Acesso em: 20 de julho de 2018.

BAHAL, G.; RAISSI, M.; TULIN, V. Croding-out or crowding-in? Public and private investment in India. World Development, maio/2018.

DOI: https://doi.org/10.1016/j.worlddev.2018.05.004

CRUZ, B. O. TEIXEIRA. J. R. The impact of public investment on private investment in Brazil, 1947-1990. Cepal Review, nº 67, abril/1999.

DAVIDSON, P. Finance, funding, savings and investment. Journal of Post Keynesian Economics/Fall. Vol IX, no 1, 1986.

DOS SANTOS, C.; PIRES, M. C. C. Qual a Sensibilidade dos Investimentos Privados a Aumentos na Carga Tributária Brasileira? Uma Investigação Econométrica. 2007.

FERREIRA, P. C. Investimento em infra-estrutura no Brasil: fatos estilizados e relações de longo prazo. Pesquisa e Planejamento Econômico, v. 26, n², ago. 1996.

GORDON, D. M. WEISSKOPF, T. E. e BOWLES, S. Power, profits and investment: an institutionalist explanation of the stagnation of U.S. net investment after the mid-1960s. Economics and Social Justice, p. 237-263, 1999.

IBGE (2018). Instituto Brasileiro de Geografia e Estatística. Disponível em <www.ibge.gov.br> Acesso em: 3 de agosto de 2018.

IPEA (2018). Ipeadata: base de dados macroeconômicos. Disponível em <www.ipeadata.gov.br> Acesso em: 3 de agosto de 2018.

JACINTO, P. A.; RIBEIRO, E. P. Co-integração, efeitos crowding-in e crowding-out enter investimento público e privado no Brasil: 1973-1989. Revista Teoria e Evidência Econômica, vol. 6, n ${ }^{\circ}$ 11, p. 143-156, 1998.

JOHANSEN, S. Estimation and Hypothesis Testing of Cointegration Vectors in Gaussian Vector Autoregressive Models. Econometrica, vol. 59, nº6, p. 1551 - 1580, 1991.

DOI: https://doi.org/10.2307/2938278

LAVOIE, M. Do heterodox theories have anything in common? A post-keynesian point of view. Journal of Economics, vol. 3, n ${ }^{\circ} 1$, p. 87-112, 2006.

DOI: https://doi.org/10.4337/ejeep.2006.01.08 
LAVOIE, M.; RODRÍGUEZ G.; SECCARECCIA M. Similitudes and discrepancies in post-Keynesian and Marxist theories of investment: A theoretical and empirical investigation. International Review of Applied Economics, vol. 18, n² 2, p. 127-149, abril/2004. DOI: https://doi.org/10.1080/0269217042000186697

MAHMOUDZADEH, M.; SADEGHI, S.; SADEGHI, S. Fiscal Spending and Crowding out effect: a comparison between developed and developing countries. Institutions and Economies, vol. 5, nº 1, p. 31 - 40, abril/2013.

MELO, G.; RODRIGUES, W. Determinantes do Investimento Privado no Brasil: 19701995. Artigos Ipea, n 605, Brasília, 1998.

. Investimento Privado no Brasil: Equações de Curto e Longo Prazos.

Revista Econômica do Nordeste, vol. 30, nº4, p. 1052-1072, out-dez/1999.

MUNDSCHENK, S. et al. Estimating an Investment Function. Disponível em <www.stefancollignon.de/Word/Tobins\%20q.doc> Acesso em 26 julho de 2018.

PATTERSON, K. An introduction to Applied Econometrics: a time series approach. New York: St. Martin's Press, 2000.

RIBEIRO, M. B.; TEIXEIRA, J. R. An econometric analysis of private-sector investment in Brazil. Cepal Review, n74, agosto 2001.

ROCHA, C. e TEIXEIRA, J. Complementaridade versus substituição entre investimento público e privado na economia brasileira: 1965-90. Revista Brasileira de Economia, vol. 50, n³, jul/set. 1996.

RONCI, M. V. Uma nota sobre a especificação da função de investimento agregado para países em desenvolvimento. Revista Brasileira de Economia, vol. 42, 1988.

SONAGLIO, C. M.; BRAGA, M. J.; CAMPOS, A. C. Investimento público e privado no Brasil: evidências dos efeitos crowding-in e crowding-out no período de 1995-2006.

Revista EconomiA, v.11, n², p.383-401, 2010.

VERBEEK, M. A Guide to Modern Econometrics. West Sussex: John Wiley and Sons, 2005. 